\title{
The treatment of schizophrenia - the state of the evidence Stefan Leucht
}

Address: Department of Psychiatry, Technische Universitot Mónchen, Germany

from International Society on Brain and Behaviour: 3rd International Congress on Brain and Behaviour

Thessaloniki, Greece. 28 November - 2 December 2007

Published: 17 April 2008

Annals of General Psychiatry 2008, 7(Suppl I):S69 doi:10.1186/1744-859X-7-SI-S69

This abstract is available from: http://www.annals-general-psychiatry.com/content/7/SI/S69

(c) 2008 Leucht; licensee BioMed Central Ltd.

There is a constantly growing body of evidence concerning the pharmacological treatment of schizophrenia. For example, the register of controlled trials of the Cochrane Schizophrenia Group currently contains more than 8000 publications. In this context the lecture will present the current state of the art of the pharmacological treatment of schizophrenia, but using a step by step algorithm from the choice of drug for the acutely patient to effective maintenance treatment for relapse prevention. The following points will be covered: choice of drug, typical versus atypical antipsychotics, which atypical antipsychotic, strategies for agitated patients, negative symptoms, depression, duration of an antipsychotic drug trial, strategies after initial non-response, clozapine, duration-, dose and choice of drug in maintenance treatment. Methodological issues in this competitive area will also be addressed. 